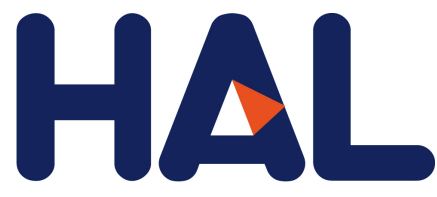

archives-ouvertes

\title{
FIM-ATOM PROBE STUDY OF THE PRECIPITATION IN A Ti46.3. Ni53.7 ALLOY
}

\author{
J. Swens, P. Willemse, J. Beyer
}

\section{To cite this version:}

J. Swens, P. Willemse, J. Beyer. FIM-ATOM PROBE STUDY OF THE PRECIPITATION IN A Ti46.3. Ni53.7 ALLOY. Journal de Physique Colloques, 1988, 49 (C6), pp.C6-359-C6-364. 10.1051/jphyscol:1988662 . jpa-00228159

\section{HAL Id: jpa-00228159 https://hal.archives-ouvertes.fr/jpa-00228159}

Submitted on 1 Jan 1988

HAL is a multi-disciplinary open access archive for the deposit and dissemination of scientific research documents, whether they are published or not. The documents may come from teaching and research institutions in France or abroad, or from public or private research centers.
L'archive ouverte pluridisciplinaire HAL, est destinée au dépôt et à la diffusion de documents scientifiques de niveau recherche, publiés ou non, émanant des établissements d'enseignement et de recherche français ou étrangers, des laboratoires publics ou privés. 
JOURNAL DE PHYSIOUE

Colloque C6, supplément au $n^{\circ} 11$, Tome 49, novembre 1988

FIM-ATOM PROBE STUDY OF THE PRECIPITATION IN A $\mathrm{TI}_{46.3}$. $\mathrm{Ni}_{53.7}$ ALIOY

\author{
J.J. SWENS, P.F. WILLEMSE* and J. BEYER* \\ SGM, Foundation for Advanced Metals Sclence, PO Box 8039. \\ NL-7550 KA Hengelo (O), The Netherlands \\ University of Twente, Faculty of Mechanical Engineering, Laboratory \\ of Materials Sclence, $P O B O X$ 217, NL-7500 AE Enschede, The Netherlands
}

\begin{abstract}
The precipitation process in a B2-TiN1-alloy has been studied during aging between 873-973 $\mathrm{K}$ for varlous aging times. Earlier reported results obtained with TEM/EDXanalyses showed the development of three different precipitates. The compositions, based on crystallographic calculations were found to be between 55-65 at \% Ni. In the present study FIM/AP-analyses have been used to verify these compositional variations. At the early stages of precipitation only $\mathrm{Ti}_{3} \mathrm{Ni}_{4}$ is formed which could be analysed both by EDX as well as FIM/AP-analysis. The results of AP-analysis seem to be in better agreement with the calculated value of 57.1 at \% $\mathrm{Ni}$ than the EDX results.

The FIM images of the alloys show no crystallographic poles which is ascribed to the heavily twinned martensite transformation of the ordered B2-phase during cooling in the FIM. The $\mathrm{Ti}_{3} \mathrm{Ni}_{4}$-phase could be identified in the FIM Images by the brightness and clear pole formation. The $\mathrm{Ti}_{2} \mathrm{Ni}_{3}-$ and the $\mathrm{Ti}{ }_{5} \mathrm{Ni}_{9}$-phase showed very brittle behaviour in the PIM, and AP-analyses showed better agreement with the calculated values than EDX, but can not be treated as conclusive yet.
\end{abstract}

\title{
1 - INTRODUCTION
}

TIN1 alloys with near equiatomic composition (B2-phase) belong to the practically used shape memory alloys. The remarkable influence of the presence of precipitates on the shape memory effect (SME) like the occurrence of the all-round SME, has initiated a growing interest in the aging behaviour of these alloys. The precipitation process in alloys with excess $N i$ concentrations has been described as $\beta_{0} \rightarrow \beta_{1}+\mathrm{Ti}_{3} \mathrm{Ni}_{4} \rightarrow \beta_{2}+\mathrm{Ti}_{2} \mathrm{Ni}_{3} \rightarrow \beta_{3}+\mathrm{TiNi}_{3}[1]$. The suggested compositions were based on crystallographic analysis of electron diffraction patterns. Chemical analysis by EDX however shows a systematical lower composition for all precipitates. Recently we reported a third metastable precipitate in a 53.7 at $\% \mathrm{Ni}$ alloy with an equiaxed morphology having a cubic lattice with a lattice paramater close to $a=0.88 \mathrm{~nm}$ [2]. Field ion microscopy of TiNi-alloy has been reported only in diluted alloys of $\mathrm{Ti}$ in $\mathrm{Ni}[3,4]$. The early stages of phase transformation (spinodal decomposition) has been reported in these references. Ne/He-gas was used for imaging these alloys. A rellable Ap-analysis was found for pulse fractions of $20 \%$ or higher. For near equiatomic TiNi alloys no information is available as yet. In this paper we will describe the use of FIM/AP-analyses to verify the consistancy of different techniques in obtaining the compositions of the different phases.

\section{2 - EXPERIMENTAL}

A binary TiNi alloy with 53.7 at \% Ni was prepared from 50.3 at \% Ni alloy (Timet Corporation) and $\mathrm{Ni}$ of $99.95 \%$ purity by arc melting in argon atmosphere. The buttons were remelted seven times-for solution treatment. Final homogenization was performed by annealing at $1323 \mathrm{~K}$ for $350 \mathrm{ks}$. in a quartz tube under low pressure argon and quenched by breaking the tube under water. Slices of 0.25 mm thickness were cut using a boron nitride cutting wheel and than aged between 873-973 $\mathrm{K}$ for different perfods. Specimens were ground from the aged slices and electrolytically polished using a three stage method in $6 \%$ perchloric acid in acetic acid and $6 \%$ perchloric acid in 2-butoxy ethano1. The original alloy with 50.3 at $\% \mathrm{NI}$ was chosen as a reference for FIM-imaging and APanalysis. Anlytical electron microscopy (Jeol $200 \mathrm{CX}$ ) was used for crystallographic and morphological study whereas chemical analyses of thin foil specimens were performed with a Link EDX-analyser. A VG-FIM 100 was used for FIM- and AP-analysis. Tip temperatures varying from 30 to 
$80 \mathrm{~K}$ and imaging gas mixtures varying from pure Ne to $50 / 50 \mathrm{NE}-\mathrm{HE}$ were investigated to determine the best imaging conditions. The lmaging gas pressure was $10^{-5} \mathrm{~Pa}$. For AP-analyses high voltage pulse ratios of 15 and $20 \%$ were used to prevent preferential evaporation of one component. A fixed tip to screen distance of $55 \mathrm{~mm}$ was used. This implies a projected probe hole on the specinen varying from 2 to $4 \mathrm{~nm}$.

\section{3 - RESULTS AND DISCUSSION}

Fig. 1 shows a low magnification micrograph of a specimen overaged at $973 \mathrm{~K}$ for $7.2 \mathrm{ks}$. The different morphologies of the metastable phases are indicated whereas the stable TiNi 3 intermetallic phase is not yet found. The thin lenticular plates (indicated as 1 ) are identified as the coherent rhombohedral phase with $a=0.672 \mathrm{~nm}, \beta=113.9^{\circ}$ and composition $\mathrm{Ti}_{3} \mathrm{Ni}_{4}$. Large $^{\circ}$ plate precipitates (marked 2) can be seen on both sides of the grain boundary. This phase has been identified as $\mathrm{Ti}_{2} \mathrm{Ni}_{3}$ with a monoclinic crystal structure with $\mathrm{a}=0.414 \mathrm{~nm}, \mathrm{~b}=0.828 \mathrm{~nm}$, c $=$ $1.352 \mathrm{~nm}$ and $\gamma=89.3^{\circ}$. The third identified phase (marked 3 ) is a cubic phase with $a=0.88 \mathrm{~nm}$ which is coherent with the $B 2$ phase.

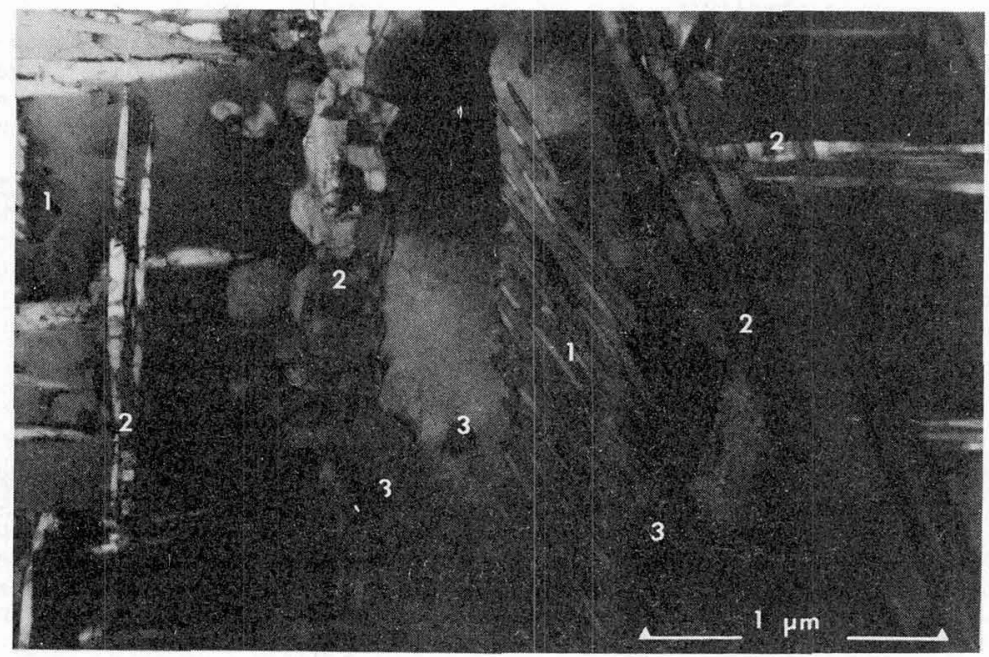

Fig. 1- Electron micrograph of an overaged 53.7 at $\% \mathrm{Ni}$ specimen with different precipitated phases; 1: $\mathrm{Ti}_{3} \mathrm{Ni}_{4} ; 2: \mathrm{Ti}_{2} \mathrm{Ni}_{3}$; 3: $\mathrm{Ti}_{5} \mathrm{Ni}_{9}$.

The chemical compositions of these phases have been determined by EDX-analysis on thin foils. The results are given in Table 1. There are some difficulties in interpreting EDX-results in general and the present results in particular which has to be born in mind. The results are obtained with the standardless method using thin foil approximation. Care has to be taken that the analysis is performed on phases which are large enough to maintain through the whole thickness of the foil and that phases are not in diffracting conditions. If not so misleading results can be obtained. Our measured values can be seen from Table 1 .

Table 1.

Compositions of three precipitated phases obtained by crystallographic calculations ( $\left.C_{\text {calc }}\right)$ and EDX-analysis $\left(C_{E D X}\right)$. (Average values of 5 measurements are shown)

\begin{tabular}{cccc}
\hline \multicolumn{2}{c}{ Phase } & $\mathrm{C}_{\text {calc, at } \% \mathrm{Ni}}$ & $\mathrm{C}_{\text {EDX }}$ at \% Ni \\
\hline 1 & $\left(\mathrm{Ti}_{3} \mathrm{Ni}_{4}\right)$ & 57.1 & 55.7 \\
2 & $\left(\mathrm{Ti}_{2} \mathrm{Ni}_{3}\right)$ & 60 & 57.8 \\
3 & $\left(\mathrm{Ti}_{5} \mathrm{Ni}_{9}\right)$ & 64.1 & 59.5 \\
\hline
\end{tabular}


The results show compositions which are systematically lower than those given by the crystallographic calculations. Although these phases are ordered, some deviation from stoichiometry could be explained by the presence of substitutional vacancies due to the aging treatment. Futhermore the accuracy of the standardless EDX-technique is not better than a few percent which means that small differences in composition like in the present material are difficult to determine.

In order to obtain microchemical information on the different phases firstly the imaging characteristics for FIM had to be determined. Sinclair et al. [3] investigated the local order parameter in dilute alloys of $\mathrm{Ti}$ in $\mathrm{Ni}$ by FIM. Up till now however little work is available on the imaging of equiatomic TiNi alloys. Primarely we investigated a specimen taken from the reference alloy with 50.3 at \% NI. Fig. 2 shows the micrograph and the overall composition obtained by random area AP-analysis. No indication was found for the development of poles in the image. After variation of the image gas from pure $\mathrm{Ne}$ to $\mathrm{Ne}-\mathrm{He}$ mixtures with $10,20,50 \%$ He best imaging was found with the $20 \%$ He mixture.

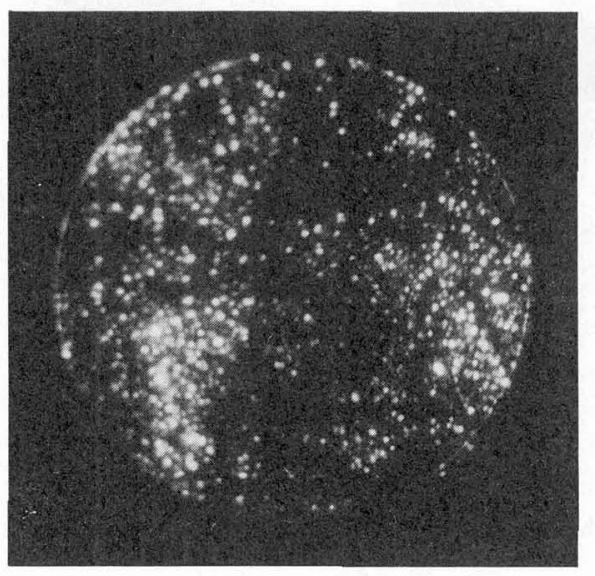

Fig. 2a - FIM-micrograph of the 50.3 at \% Ni alloy

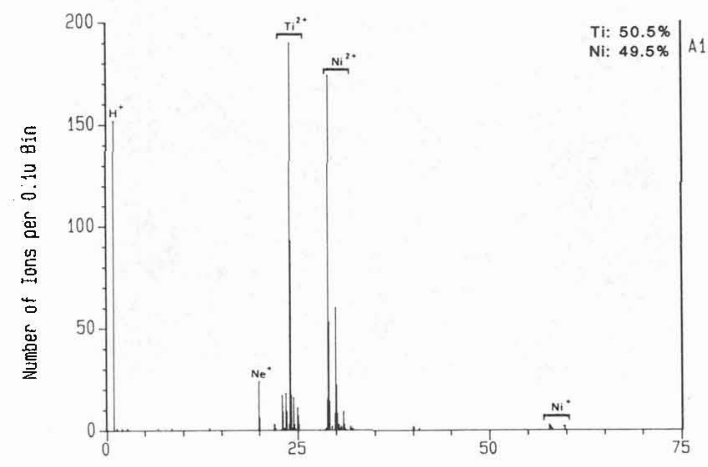

Hass-to charge Ratio

Fig. 2b - AP-spectrum of the 50.3 at $\% \mathrm{Ni}$ alloy

Imaging of the material was expected to be difficult due to the following arguments. While cooling the FIM-tip down to $30 \mathrm{~K}$ the ordered B2 high temperature phase transforms to monoclinic martensite with a very high density of twins and transformation dislocations. These martensite boundaries are visible as dark bands in the FIM-image (Fig. 2). Additionally the high electric fleld may. plastically strain the martensite due to its very low elastic limit. This has frequently led to catastrophic failure of the FIM-tips. The difference in ionization fields of Ne for $T i$ and $N 1$ may cause different contrast of the respective species and it is probable as indicated elswhere [3] that $\mathrm{Ni}$ will be the imaging species. The AP-spectrum also shows a large amount of $\mathrm{H}^{+}$originating from the polishing procedure. The compositions of 49.5 at \% $\mathrm{Ni}$, obtained by AP-analysis is in satisfactory agreement with the chemical analysis giving 50.3 at $\% \mathrm{Ni}$.

Specimens with 53.7 at $\% \mathrm{Ni}$, homogenized at $1323 \mathrm{~K}$ were subsequently imaged in the FIM. Fig. 3 shows the FIM- and TEM-images. An early stage of homogeneous precipitation of the $\mathrm{Ti}_{3} \mathrm{Ni}_{4} \mathrm{phase}$ is visible in the TEM-image. This was confirmed by electron diffraction. The precipitate size was less than $10 \mathrm{~nm}$. The FIM-image shows a small bright area with a clear pole. Although this precipitate which is taken to be $\mathrm{Ti}_{3} \mathrm{Ni}_{4}$, is coherent with the $\mathrm{B} 2$ phase no continuity of the observed poles was visible in the matrix. Despite the relatvive high Ni-concentration and thus a very low Ms temperature the transformation to martensite may still have occurred giving rise to strains which will mask the poles. The compositions obtained by AP-analysis from the areas indicated as precipitates, were in acceptable agreement with the calculated values. The concentration profile showed fluctuations in the composition which indicate the presence of precipitates. The size of the fluctuations is of the same order as measured from TEM-images.

Fig. 4 shows the TEM-image of the tip for a specimen aged at $873 \mathrm{~K}$ for $3.6 \mathrm{ks}$. TEM-analysis indicated the presence of both $\mathrm{Ti}_{2} \mathrm{Ni}_{3}$ and $\mathrm{Ti}_{3} \mathrm{Ni}_{4}$ precipitates, where $\mathrm{Ti}_{3} \mathrm{Ni}_{4}$ precipitates were found to be relative large. AP-analyses for the matrix and both precipitates are given in Fig. $5 a-$ 
c. The composition profile of the matrix shows fluctiations within a few percent due to the depletion of $\mathrm{Ni}$ into the precipitate. The overall matrix composition is 50.9 at \% Ni. The composition for the $\mathrm{Ti}_{3} \mathrm{Ni}_{4}$ precipitates were found to vary between 56.6 and 57.4 at $\% \mathrm{Ni}$ and for $\mathrm{Ti}_{2} \mathrm{Ni}_{3}$ precipitates between 59.6 and 60.6 at \% $\mathrm{Ni}$, ali again in acceptable agreement with the calculated values. In specimens aged at $973 \mathrm{~K}$ for $7.2 \mathrm{ks}$, the same composition for the $\mathrm{Ti}_{2} \mathrm{Ni}_{3}$ was found and ocassionally a precipitate composition of 65.2 at \% Ni was measured. Although these results are not conclusive they strongly indicate that using FIM/AP-analysis accurate measurements of compositional variations due to precipitation in TiNi-SME alloys are possible.

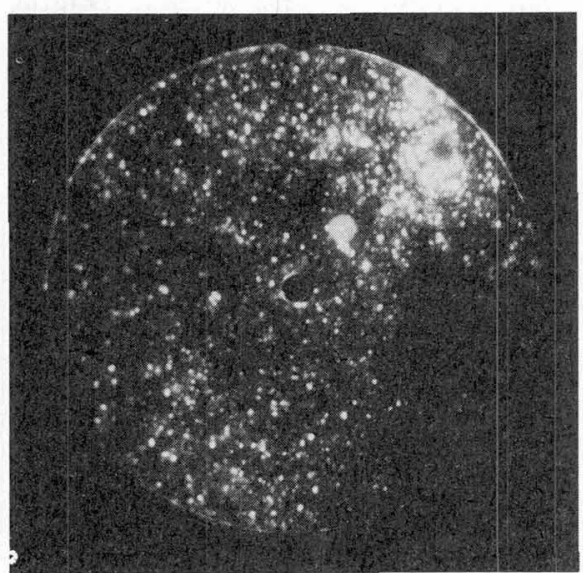

Fig. 3a - FIM-micrograph of the homogenized 53.7 at $\% \mathrm{Ni}$ alloy

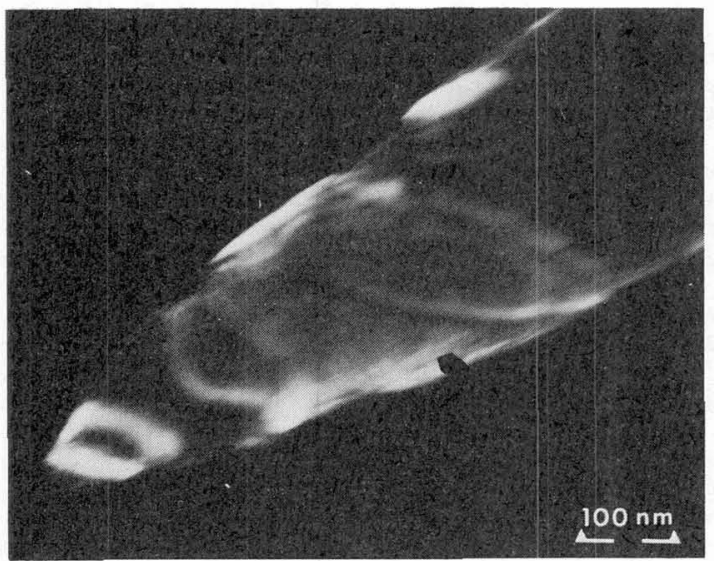

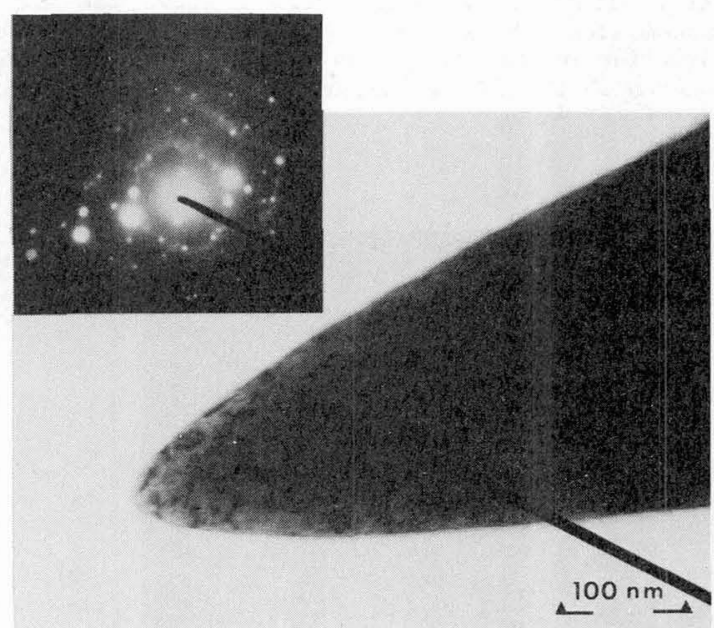

Fig. 3b - Electron-mircograph and diffraction pattern of the homogenized 53.7 at $\%$ Ni alloy tip
Fig. 4 - Electron-micrograph of the 53.7 at $\% \mathrm{Ni}$ alloy tip aged at $873 \mathrm{~K}$ for $3.6 \mathrm{ks}$ 

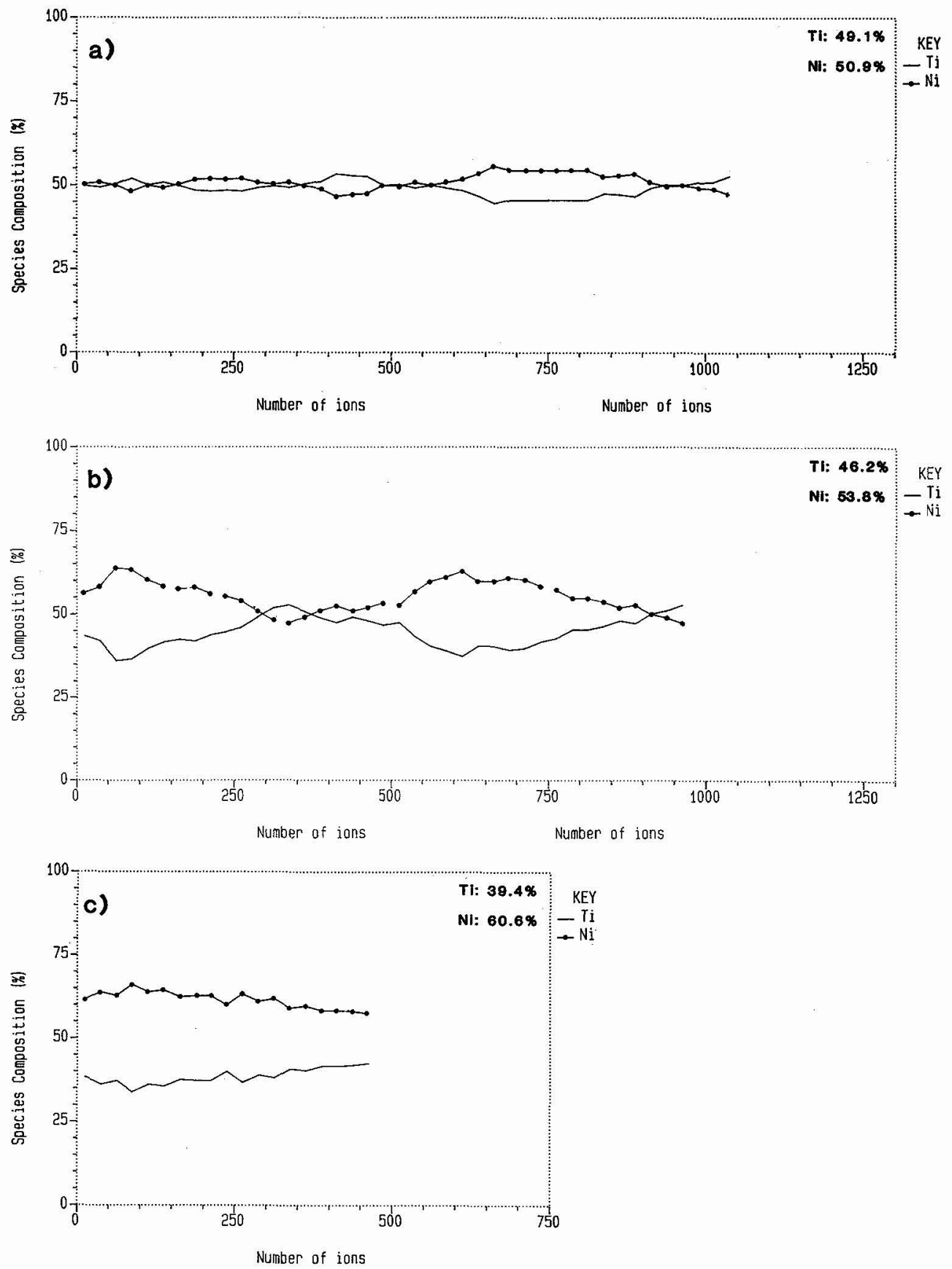

Fig. 5 - AP composition profiles of the 53.7 at $\% \mathrm{Ni}$ alloy aged at $873 \mathrm{~K}$ during $3.6 \mathrm{ks}$ for a) matrix b) $\mathrm{Ti}_{3} \mathrm{Ni}_{4}$ precipitates c) $\mathrm{Ti}_{2} \mathrm{Ni}_{3}$ precipitates. $\mathrm{T}=55 \mathrm{~K}$ 
4 - CONCLUSIONS

- FIM-imaging near equiatomic TiNi alloys has been shown to be possible with a Ne-He mixture at $30 \mathrm{~K}$.

- $\mathrm{Ti}_{3} \mathrm{Ni}_{4}$ precipitates show clear poles. Specimens with fine homogeneously nucleated precipitates show to be more stable with respect to failure than those with coarse precipitates.

- Formation of martensite during cooling to imaging temperatures can cause early failure of the tips.

- Compositions of the matrix, $\mathrm{Ti}_{3} \mathrm{Ni}_{4}$ and $\mathrm{Ti}_{2} \mathrm{Ni}_{3}$ precipitates obtained by AP-analysis are in better agreement with those calculated from crystallographic data than the compositions obtained with EDX-analysis.

\section{5 - REFERENCES}

1. Nishida, M. and Wayman, C.M., Mater. Scl. Eng. 93 (1987) 191.

2. Beyer, J., V.d. Brakel, R.A. and Lloyd, J.A.R.T., Proc. ICOMAT 86, Nara, Japan (1986) 703.

3. Sinclair, R., Ralph, B. and Leake, J.A., Phil. Mag. 28 (1973) 1111.

4. Watts, A.J. and Ralph, B., Surface Sci. 70 (1978) 459. 